\title{
Developing a Framework for Entrepreneurs to Transform Their Ideas into Businesses: A Case Study in the Food Sector
}

\author{
Rami H. Alamoudi, Basim A. Alandijany \\ Department of Industrial Engineering, King Abdulaziz University, Jeddah, Saudi Arabia \\ Email: rhalamoudi@kau.edu.sa
}

How to cite this paper: Alamoudi, R.H. and Alandijany, B.A. (2017) Developing a Framework for Entrepreneurs to Transform Their Ideas into Businesses: A Case Study in the Food Sector. American Journal of Industrial and Business Management, 7 , 444-463.

https://doi.org/10.4236/ajibm.2017.74032

Received: January 31, 2017

Accepted: April 23, 2017

Published: April 26, 2017

Copyright $\odot 2017$ by authors and Scientific Research Publishing Inc. This work is licensed under the Creative Commons Attribution International License (CC BY 4.0).

http://creativecommons.org/licenses/by/4.0/

(c) (i) Open Access

\begin{abstract}
The term "entrepreneurship" refers to qualities and actions of individuals that involve taking the risks of venturing into new and unknown areas of work. It generally involves creating or setting up new enterprises that engage in activities that are significantly different from other enterprises around it. However, entrepreneurs face many obstacles, and a non-trivial number of ventures have sought to establish new businesses that could not come to fruition. In today's competitive markets, various kinds of planning techniques have become a crucial element for both new and established businesses. This study covers some outstanding strategies, namely, the Blue Ocean Strategy (BOS), Balanced Scorecard (BSC) and Continuous Improvement (KAIZEN), which have proven their effectiveness in several global industries. Furthermore, the study provides an integrated framework that aligns these strategies to serve as guidance for entrepreneurs to transform their ideas into successful enterprises. Moreover, the study demonstrates a practical implementation of the framework in Talah Aljood Company, which was ranked first by Forbes Middle East in 2014 in the food and beverage sector. It is concluded that the gist of today's successful enterprises is value innovation, planning and continuous improvement. Therefore, the developed framework covers these three pillars in an integrated manner to avoid any possible gaps that may occur during these phases.
\end{abstract}

\section{Keywords}

Enreperneuship, Blue Ocean Strategy, Balanced Scorecard

\section{Overview}

In the past, it was believed that small businesses were less efficient economic 
wise than large ventures. However, since the last few decades of the twentieth century, the opposite point of view has been taken. Recently, entrepreneurship has come to be a subject of interest, especially for economists. It has become an engine of growth and one of the most important players in the modern economy. Numerous societal benefits are associated with entrepreneurship. It drives innovation, decreases unemployment and satisfies new consumer demands.

The term "entrepreneurship" refers to the qualities and actions of individuals that involve taking the risk of venturing into new and unknown areas of work. It generally involves creating or setting up new enterprises that engage in kinds of activities that are significantly different in some way from those of other enterprises around it. However, having an idea for a new area of work is not sufficient for starting a business, unless the implication of the assigned idea is assessed using a reliable scientific approach.

This study reviews multiple outstanding strategies with proven effectiveness in several global industries, namely, the Blue Ocean Strategy (BOS), Balanced Scorecard (BSC) and Continuous Improvement (KAIZEN). Moreover, the study provides an integrated framework that aligns these strategies to serve as guidance for entrepreneurs who want to transform their ideas into businesses.

To give a clear perception of how the framework can be implemented, the researcher chose one of the most successful entrepreneurial businesses in the date market in Saudi Arabia to be a case study for the research, Talah Aljood Company. It specializes in the traditional Arabian hospitality of dates, complementary sweets, drinks, and Arabian coffee made from the finest coffee beans and cardamom. It works extremely hard to offer the essence of tradition with a modern twist.

\subsection{Statement of the Problem}

Entrepreneurship enjoys a high level of support in Saudi Arabia; the Kingdom has led the Arab region in terms of regulatory reforms related to entrepreneurship. According to the report of Doing Business (DB), the country ranked 13th globally and maintained its position in first place in the region on the ease of doing business [1]. In the latest World Economic Forum (WEF) Global Competitive Index, it moved up seven places from 28th to 21st, which resulted from a strong and solid institutional framework, efficient markets, and sophisticated businesses places [2]. The Enactment of a new foreign investment law, the establishment of the Saudi Arabian General Investment Authority (SAGIA) and the privatization of public companies in recent years have encouraged investments in the country.

However, entrepreneurs still face difficulties. A non-trivial number of ventures have sought to establish new businesses that failed quickly after starting. In such a competitive market, entrepreneurial strategies are becoming more important for both new and established businesses. Due to, e.g., increasing environmental dynamics and intensifying global competition, entrepreneurs, regardless of their business age or size, are recommended to depend on a clear 
scientific framework to achieve the business' targets and compete in the market.

The main focus of this study is to develop a scientific framework that can be used by entrepreneurs to form new innovative businesses in which they can achieve their targets and survive among such strong competition in the market locally and globally.

\subsection{Aim of the Project}

The main objective of this study is to develop a scientific practical framework that integrates multiple strategies and techniques to serve as guidance for entrepreneurs in transforming their ideas into more successful and sustainable businesses.

\subsection{Objectives}

The researcher aimed to develop a framework that addresses multiple integrated strategies, namely, the blue ocean strategy (BOS), Balanced Scorecard (BSC) and Continuous Improvement (CI) to cover the following objectives:

- Developing a competitive strategy by creating an uncontested market space.

- Determining the long-term strategic objectives and short-term operational objectives.

- Evaluating businesses using the key performance indicators (KPIs).

- Designing a continuous improvement plan for businesses.

\subsection{Methodology}

- Phase I: Blue Ocean Strategy

- Market Analysis.

- Analyzing the ERRC Grid.

- Developing the strategy canvas.

- Phase II: Balanced Scorecards

- SWOT Analysis.

- Assessing the business vision, mission \& values.

- Determining the strategic objectives.

- Developing the strategy map.

- Setting the key performance indicators.

- Developing initiatives toward the strategic objectives.

- Cascading the strategic objectives into operational objectives.

- Evaluating the business.

- Phase III: Continuous Improvement

- Selection of KAIZEN theme.

- Situation analysis.

- Root cause analysis.

- Identification of countermeasures.

- Implementation of the identified countermeasures.

- Check effectiveness of the countermeasures.

- Standardization of effective countermeasures. 


\subsection{Scope of the Study}

The study focuses on developing the mentioned framework, which includes the Blue Ocean Strategy (BOS), Balanced Scorecard (BSC) and Continuous Improvement (KAIZEN), and providing a case study to show the practical implementation in the food sector in Saudi Arabia.

\section{Literature Review}

\subsection{Entrepreneurship}

Although entrepreneurship is one of the most popular topics of this time, the most pressing task is defining entrepreneurship. It should be stated that there is no general agreement about the meaning of this term. There are two distinctly different approaches in defining entrepreneurship. The first is to define what entrepreneurs are and then observe them. The second is to propose a prior definition of entrepreneurship and its related behaviors and thereby define entrepreneurs as those who engage in entrepreneurial activity.

In the 19th century, Jean Baptiste Say came up with his definition for an entrepreneur. He mentioned that the entrepreneur shifts economic resources out of an area of lower productivity and into an area of higher productivity and greater yield [3]. Since Say's definition, there has been total confusion over the definition.

The modern understanding of an entrepreneur could be described as a person who destroys the existing economic order by introducing new products and services, by introducing a new method of production, by creating new forms of organizations, or by exploiting new raw materials [4]. To Joseph Schumpeter, entrepreneurship occurs when there is innovation in the introduction of a new product, organization or process. Hence, his understanding of an entrepreneur was a conceptual abstraction characterized by the creation of new combinations [5]. Additionally, he makes the distinction between five different manifestations of entrepreneurship; a new good, a new method of production, a new market, a new source of supply of intermediate goods, and a new organization. Hitherto, the problem of defining the word 'entrepreneur' and establishing the boundaries of the field of entrepreneurship have not been solved [6]. In 1999, Wennekers and Thurik presented a wide picture of entrepreneurship, noting that it is the manifest ability and willingness of individuals, on their own, in terms, within and outside existing organizations, to perceive and create new economic opportunities (new product, new production methods, new organizational schemes and new-market combinations) and to introduce their ideas in the market, in the face of uncertainty and other obstacles, by making decisions on location and the use of resources and institutions [7]. In contrast, Acs and Audretsch's definition embraces all businesses that are new and dynamic, regardless of size or line of business, will excluding businesses that are neither new nor dynamic as well as all nonbusiness organizations [8].

\subsection{Blue Ocean Strategy (BOS)}

The Blue Ocean Strategy is a strategy developed in 2005 and written by W. Chan 
Kim and Renée Mauborgne, Professors at INSEAD and Co-Directors of the INSEAD Blue Ocean Strategy Institute. Based on a study of 150 strategic moves spanning more than a hundred years and thirty industries, Kim \& Mauborgne argue that companies can succeed not by battling competitors, but rather by creating "blue oceans" of uncontested market space. They assert that these strategic moves create a leap in value for the company, its buyers, and its employees, while unlocking new demand and making the competition irrelevant. The strategy presents analytical frameworks and tools to foster an organization's ability to systematically create and capture blue oceans [9]. Kim and Mauborgne [10] argue that while traditional competition-based strategies (red ocean strategies) are necessary, they are not sufficient to sustain high performance. Companies need to go beyond competing. To seize new profits and growth opportunities, they also need to create blue oceans. The authors argue that competition-based strategies assume that an industry's structural conditions are given and that firms are forced to compete within them, an assumption based on what academics call the structuralism view, or environmental determinism. To sustain themselves in the marketplace, practitioners of a red ocean strategy focus on building advantages over the competition, usually by assessing what competitors do and striving to do it better. Here, grabbing a larger share of the market is seen as a zero-sum game in which one company's gain is achieved at another company's loss. Hence, competition, the supply side of the equation, becomes the defining variable of strategy. Here, cost and value are seen as trade-offs and a firm chooses a distinctive cost or differentiation position. Because the total profit level of the industry is also determined by structural factors, firms principally seek to capture and redistribute wealth instead of creating wealth. They focus on dividing up the red ocean, where growth is increasingly limited. The blue ocean strategy, in contrast, is based on the view that market boundaries and industry structure are not given and can be reconstructed by the actions and beliefs of industry players. This is what the authors call the Reconstructionist view. Assuming that structure and market boundaries exist only in managers' minds, practitioners who hold this view do not let existing market structures limit their thinking. To them, extra demand is out there, largely untapped. The crux of the problem is how to create it. This, in turn, requires a shift of attention from supply to demand, from a focus on competing to a focus on value innovation-that is, the creation of innovative value to unlock new demand. This is achieved via the simultaneous pursuit of differentiation and low costs. As the market structure is changed by breaking the value/cost tradeoff, so are the rules of the game. Therefore, competition in the old game is rendered irrelevant. By expanding the demand side of the economy, new wealth is created. Such a strategy allows firms to largely play a non-zero-sum game, with high payoff possibilities. Figure 1 shows the mind map of BOS leadership.

\subsection{Balanced Scorecard (BSC)}

The Balanced Scorecard (BSC) is a strategic planning and management system 


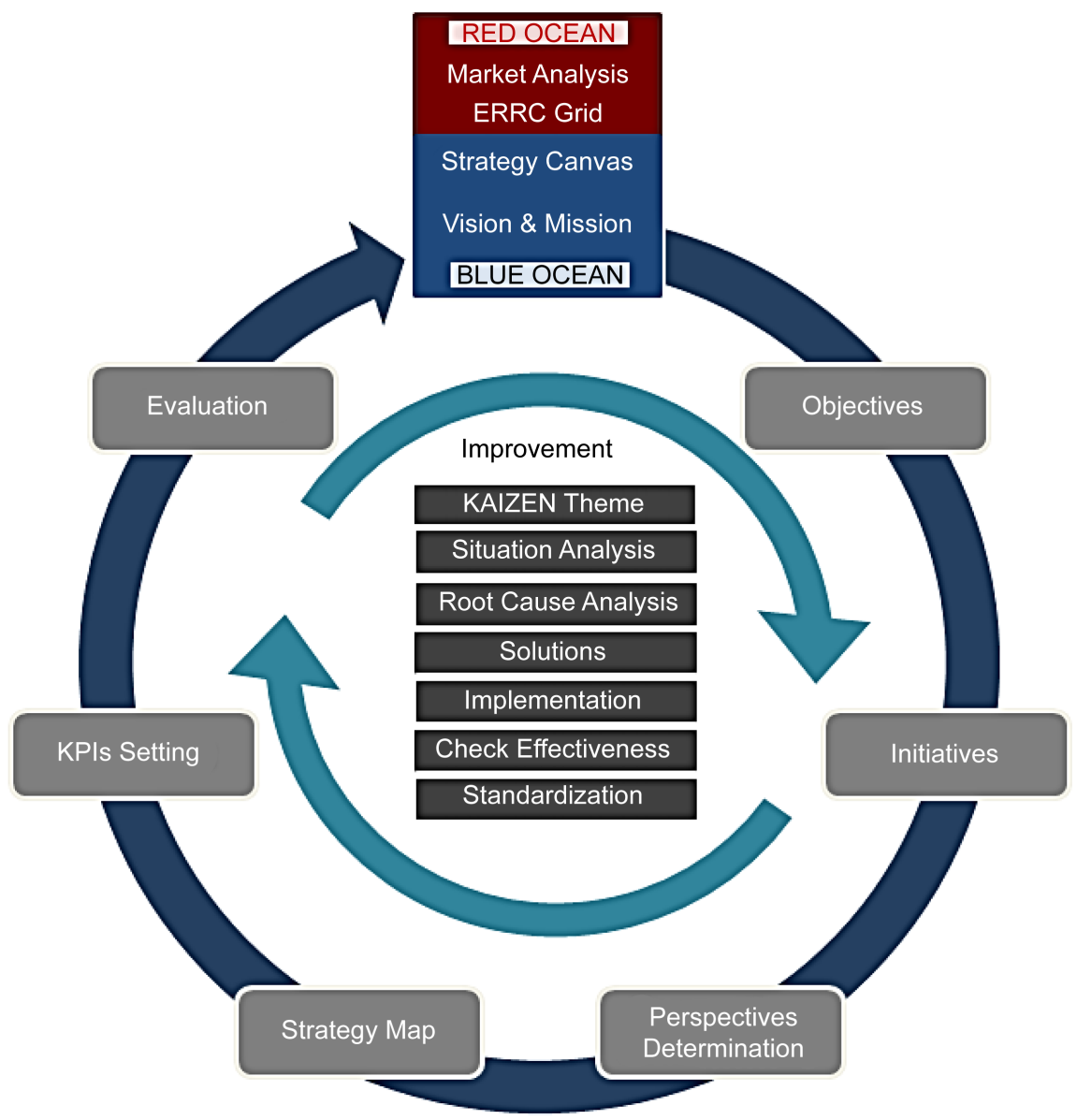

Figure 1. BBK model.

that is used extensively in business and industry, government, and even nonprofit organizations worldwide to align business activities to the vision and strategy of the organization, improve internal and external communications, and monitor organization performance against strategic goals [10].

The Balanced Scorecard has evolved from its early use as a simple performance measurement framework to a full strategic planning and management system. The "new" balanced scorecard transforms an organization's strategic plan from an attractive but passive document into the "marching orders" for the organization on a daily basis.

It provides a framework that not only provides performance measurements but also helps planners identify what should be done and measured. It enables executives to truly execute their strategies.

Kaplan and Norton describe the innovation of the balanced scorecard as follows: "The balanced scorecard retains traditional financial measures. However, financial measures tell the story of past events, an adequate story for industrial age companies for which investments in long-term capabilities and customer relationships were not critical for success.

These financial measures are inadequate, however, for guiding and evaluating the journey that information age companies must make to create future value 
through investment in customers, suppliers, employees, processes, technology, and innovation.

\subsection{Continuous Improvement (KAIZEN)}

In the 1980s, management techniques focused on employee involvement, empowerment through the teamwork approach and interactive communications. The concept of improving job design was not new, but Japanese companies seemed to implement such techniques much more effectively than others. The business lesson of the 1980s was that Japanese firms, in their quest for global competitiveness, demonstrated a greater commitment to the philosophy of continuous improvement than Western companies did. For such a philosophy, the Japanese used the term Kaizen.

Kaizen means improvement, continuous improvement involving everyone in the organization from top management, to managers, then to supervisors, and to workers. In Japan, the concept of Kaizen is so deeply engrained in the minds of both managers and workers that they often do not even realize they are thinking Kaizen as a customer-driven strategy for improvement [11]. This philosophy assumes, according Imai, that "our way of life, be it our working life, our social life or our home life, deserves to be constantly improved".

\section{The Integrated BBK Model}

\subsection{BBK Model Overview}

The gist of today's successful enterprises is value innovation, planning and continuous improvement. Therefore, the developed framework covers the first pillar through the Blue Ocean Strategy, while the planning area is covered by using the Balanced Scorecard technique, and KAIZEN concerns continuous improvement. The BBK model covers these three pillars in an integrated manner to avoid any possible gaps that might occur during these phases. Figure 1 shows the BBK Model.

\subsection{Talah Aljood Company}

Talah Aljood Company specializes in the traditional Arabian hospitality of dates, complementary sweets, drinks, and Arabian coffee made from the finest coffee beans and cardamom. The company is distinctive in its selection of the finest ingredients, its clever blending of flavors and its unmatched variety of products. It works extremely hard to offer the essence of tradition with a modern twist.

Eng. Yaser Bakker, Co-founder and CEO of Operations at Talah Aljood, is a very good example of a Saudi entrepreneur who inspires many people around the kingdom and is ranked number one in Middle East Forbes list. Bakker's portfolio may not hint at world domination just yet, but the man whose entrepreneurial drive stems from his passion for the much-loved fruit is spreading his roots. "We have distributed to gulf countries and other Arab countries such as Egypt before, as well as Saudi embassies around the world," explains the CEO, no simple feat for a company that started life as a single retail outlet with three 
employees. Launched by Bakker and his co-founders, Majed and Majdi Darwish, back in 2001, Talah Aljood (Talah means small palm tree) now boasts a staff of more than 300, and with more than 10 branches across Jeddah, Riyadh, Mecca and Medina, business is growing, with a product range to match.

In addition to the plain and stuffed date staples (Sukkari and Ajwa dates account for $50 \%$ of sales), Talah Aljood's offerings now extend to cakes, milkshakes, and traditional pastries known as Ma'amoul, all of which are manufactured in the company's Jeddah-based factory.

Bakker, who grew up between Riyadh and Jeddah alongside his three siblings, is as reluctant to divulge figures as he is to divulge the source of his produce, sharing only that initial investment in his company stood at around $\$ 400,000$. A $25 \%$ rise in sales in the last three quarters of 2013, however, points to solid growth, with a $20 \%$ annual increase anticipated over the coming years.

\subsection{Methodology}

In this study, the Talah Aljood Company is used as a case study to clarify the step-by-step methodology of the framework. It is important to note that the implementation of the BBK framework in this study was not done for the current period of the company; rather, the study concerns Talah Aljood at its very beginning of success in the period between 2001 and 2007.

\subsubsection{Phase I: Blue Ocean Strategy}

In the first phase, three main steps are involved: analyzing the market, analyzing the ERRC grid and drawing the strategy canvas. The general idea of this phase is studying the market to know the main competitors in this market, to determine the main competing factors and then to draw the strategy curve taking differentiation into consideration.

\section{1) Market Analysis}

Before getting into a new business, it is very crucial to have a clear perception about the concerned market. Without making this analysis, it is impossible to predict customers' needs and requirements.

In 2001, a study at King Saud University [12] was conducted to determine some characteristics and factors that highlight the most important indicators in the date market. The study targeted approximately 650 Saudis covering all ages, both genders, all educational levels, and all income categories. Sample characteristics are summarized in Table 1.

Some statistical tools and analysis were used on the survey data; however the focus will be on two outputs only, which are the buying criteria and the problems faced by buyers; see Figure 2 .

Moreover, the main competitors in the date market can be divided into three categories: date shops, kiosks and supermarkets.

\section{2) Analyzing the ERRC Grid}

The Eliminate-Reduce-Raise-Create (ERRC) Grid complements the Four Action Framework. It pushes companies not only to ask the questions posed in the 
Table 1. Sample profile table [12].

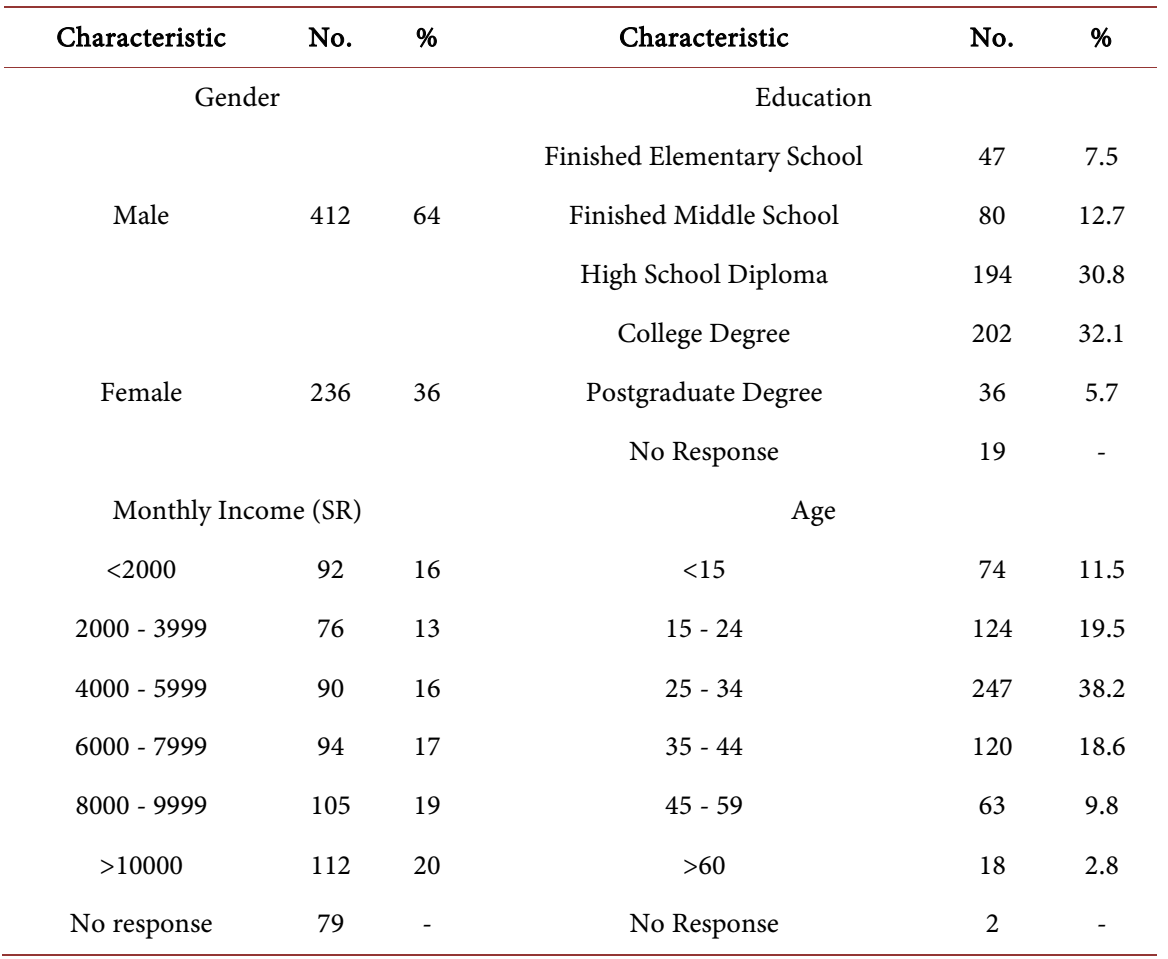

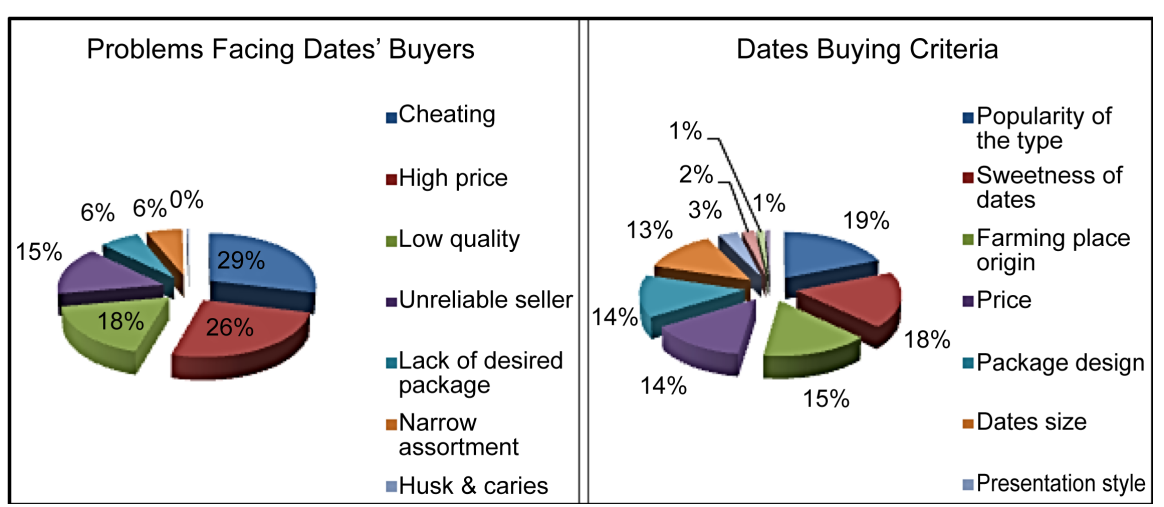

Figure 2. Customers' buying criteria \& problems [12].

Four Actions Framework but also to act on all four to create a new value curve, which is essential to unlocking a new blue ocean.

To implement this grid, it is essential first to clearly understand how other competitors contribute in the market to determine the main competing factors. As mentioned in the previous section, the main competitors in the date market in Saudi Arabia can be divided into three categories; each category has its own characteristics, which are summarized as follows:

\section{a) Dates' Shops}

The quality of dates in these shops is the best among all the categories. However, the quality can be guaranteed by no more than $80 \%$. Usually, their products are purchased for personal consumption or for guests. These products are packaged in modest boxes or dishes. This form of presentation usually is not pre- 
ferred as gifts or for guest hospitality.

The good side in these kinds of shops is that customers can find various kinds of dates with an average price and relatively good quality.

\section{b) Kiosks}

Kiosks are distributed widely in many different places. They can be found on the streets, in fruit and vegetable shopping areas, near mosques, "especially during Hajj and Ramadan period", and in many other places.

Customers in this category are searching for a large amount of dates with a cheaper price. Regarding the quality, it is not very good due to unreliable storage conditions. Kiosks offer the same kinds of products that are offered by date shops but at a cheaper price.

\section{c) Supermarkets}

Supermarkets contribute the least in the date market. They offer the cheapest dates with the lowest quality among all the competitors. Their products are usually consumed by low-income people or fill in some desserts.

After analyzing the competitors, it is much easier to determine the most important competing factors of the date market. The aspects of every competitor are highlighted through the manipulation of these factors; see Table 2.

Now, it is time to make the ERRC grid, which helps in breaking the differentiation and low cost trade-off. The ERRC grid pushes the planner to eliminate the factors that have been long competed over and hence have lost value; reduce factors that have been over-designed or that over-serve the customer; raise factors that are incumbent, provide value and are desired by the customer; and create factors that are new and for which the need is still unknown to customers. The application of this four-action framework creates a new value curve. The Talah ERRC grid is shown in Table 3.

Table 2. Competitors and competing factors.

\begin{tabular}{lc}
\hline \multicolumn{1}{c}{ Competitors } & \multicolumn{1}{c}{ Factors } \\
\hline Dates' Shops & Good Quality, Average Price, Normal Presentation, Variety of Types \\
Kiosks & Low Quality, Cheaper Price, Bad Storage, On the way \\
Supermarkets & Lowest Quality \& Price, Not Fresh \\
Price, Presentation, Quality, Variety of Type, Seller Reliability
\end{tabular}

Table 3. The ERRC grid.

\begin{tabular}{cc}
\hline Eliminate & Reduce \\
\hline Relling in another shops & Suppliers \\
Quality & Create \\
Creative Presentation & Online Orders \\
Price & Brand \\
Luxurious & Creative Products
\end{tabular}




\section{3) Strategy Canvas}

In a strategy canvas, the differences between competitors' approaches are clearly shown. The horizontal axis captures the range of factors in which the industry competes and invests, whereas the vertical axis captures the offering level that buyers receive across all of these key competing factors. See Figure 3. This canvas serves two purposes:

- To capture the current state of play in the known market space, which allows users to clearly see the factors in which the industry competes and where the competition currently invests and

- To propel users to action by reorienting the focus from competitors to alternatives and from customers to non-customers of the industry.

\subsubsection{Phase II: Balanced Scorecard (BSC)}

In the BSC technique, the values, vision, mission, strategic objectives and KPI measures are defined and aligned together. However, in this study, the scope of operational application will be only one year, " 2007 ".

\section{1) Applying SWOT Analysis}

The first step in Balanced Scorecard is applying the SWOT analysis technique, which stands for Strength, Weaknesses, Opportunities and Threats. To apply SWOT analysis, a workshop was held at Talah Company to introduce SWOT analysis and brainstorm to generate the Strength, Weaknesses, Opportunities and Threats. The results are summarized below; see Table 4.

\section{2) Cascading Strategic Objectives into Operational Objectives}

In this section, each strategic objective will be cascaded into different shortterm operational objectives to be measured using the KPIs, as shown in the following points:

Strategic objective (1): Having highly motivated and qualified staff that presents the Talah image in a suitable work environment:

1. Specialized training programs with training and consulting companies.

2. Develop rewarding programs.

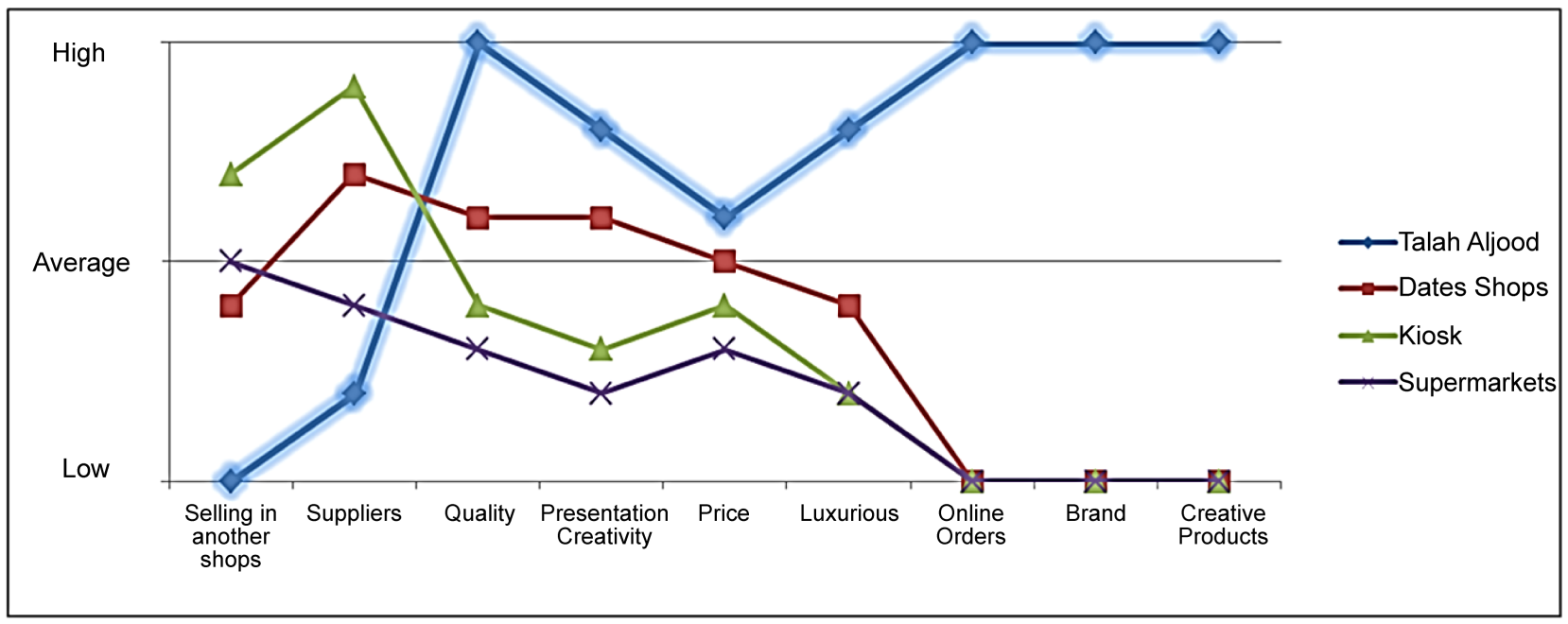

Figure 3. Strategy canvas. 
Table 4. SWOT analysis.

\begin{tabular}{cc}
\hline Strength & Weaknesses \\
\hline First mover advantage & One Time product \\
Good experience in dates & Logistics \\
Relations with suppliers & Storage Conditions \\
High demand product & Traditions \\
Opportunities & Threats \\
Corporate Business Demand & Competitors moving \\
International Business & Supplier Termination \\
Franchise & \\
\hline
\end{tabular}

3. Participate in recruitment events.

Strategic objective (2): Selling creative and non-traditional products:

1. Create new non-traditional products.

2. Conduct benchmark studies with the best chocolate and date shops.

Strategic objective (3): Having a smooth workflow and business processes:

1. Develop business processes.

2. Conduct VOC sessions.

\section{Strategic objective (4): Increasing productivity:}

1. Automate processes.

2. Apply monitoring system.

Strategic objective (5): Improving the supply chain process:

1. Own trucks for transportation.

2. Establish a warehouse.

Strategic objective (6): Expanding Talah locally and internationally:

1. Open new branches.

2. Study the feasibility of franchising.

3. Improve corporate business.

Strategic objective (7): Improving financial impact:

1. Achieve profit target.

2. Reduce costs.

\section{3) Perspectives Determination}

In this section, the aim is to group the operational objectives into four general perspectives, which are learning and growth, internal processes, customer and finance.

First perspective: Learning and growth:

The learning and growth perspective addresses the question of how the company must learn, improve, and innovate to meet its objectives. The following are the operational objectives under the learning and growth perspective:

1. Specialized training programs with training and consulting companies.

2. Conduct benchmark studies with the best chocolate and dates shops.

3. Develop rewarding programs.

4. Participate in recruitment events. 


\section{Second perspective: Internal processes:}

Internal business process objectives address the question of which processes are most important for satisfying customers and shareholders. The following are the operational objectives under the internal process perspective:

1. Automate processes.

2. Develop business process.

3. Apply monitoring system

4. Own trucks for transportation.

5. Establish a warehouse.

\section{Third perspective: Customer:}

The customer perspective addresses the question of how the company is viewed by its customers and how well the company is serving its targeted customers to meet the financial objectives. The following are the operational objectives under the customers' perspective:

1. Create new non-traditional products.

2. Open new branches.

3. Increase customer satisfaction.

4. Conduct VOC sessions.

\section{Fourth perspective: Finance:}

The Financial perspective addresses the question of how shareholders view the company and which financial goals are desired from the shareholder's perspective. The following are the operational objectives under the finance perspective:

1. Achieve profit target.

2. Improve corporate business.

3. Reduce costs.

4. Study the feasibility of franchising.

\section{4) Strategy Mapping}

Strategy Mapping is a technique that helps in representing the company's strategies in such a way that shows the cause and effect of each strategy. Its main purpose is to ensure that each strategy does really serve a specific other strategy, and the overall strategies serve and feed the company's vision. See Figure 4.

\section{5) Key Performance Indicators (KPIs) Setting}

The determination of Key Performance Indicators (KPIs) is one of the critical steps of a Balanced Scorecard. It is used to monitor how well a business is achieving its quantifiable objectives. Its purpose is to indicate and alarm the management of strategy and target achievements or deviations. If the operational objectives are not measured with the appropriate KPIs, the result will be misleading.

Furthermore, the Key Performance Indicators (KPIs) should be distinguished from Performance Indicators (PIs) to obtain accurate results.

- PI: Performance indicators are more focused on smaller targeted areas and less powerful than KPIs. In addition, they may be misleading because they are not directly related to the strategic objectives. 


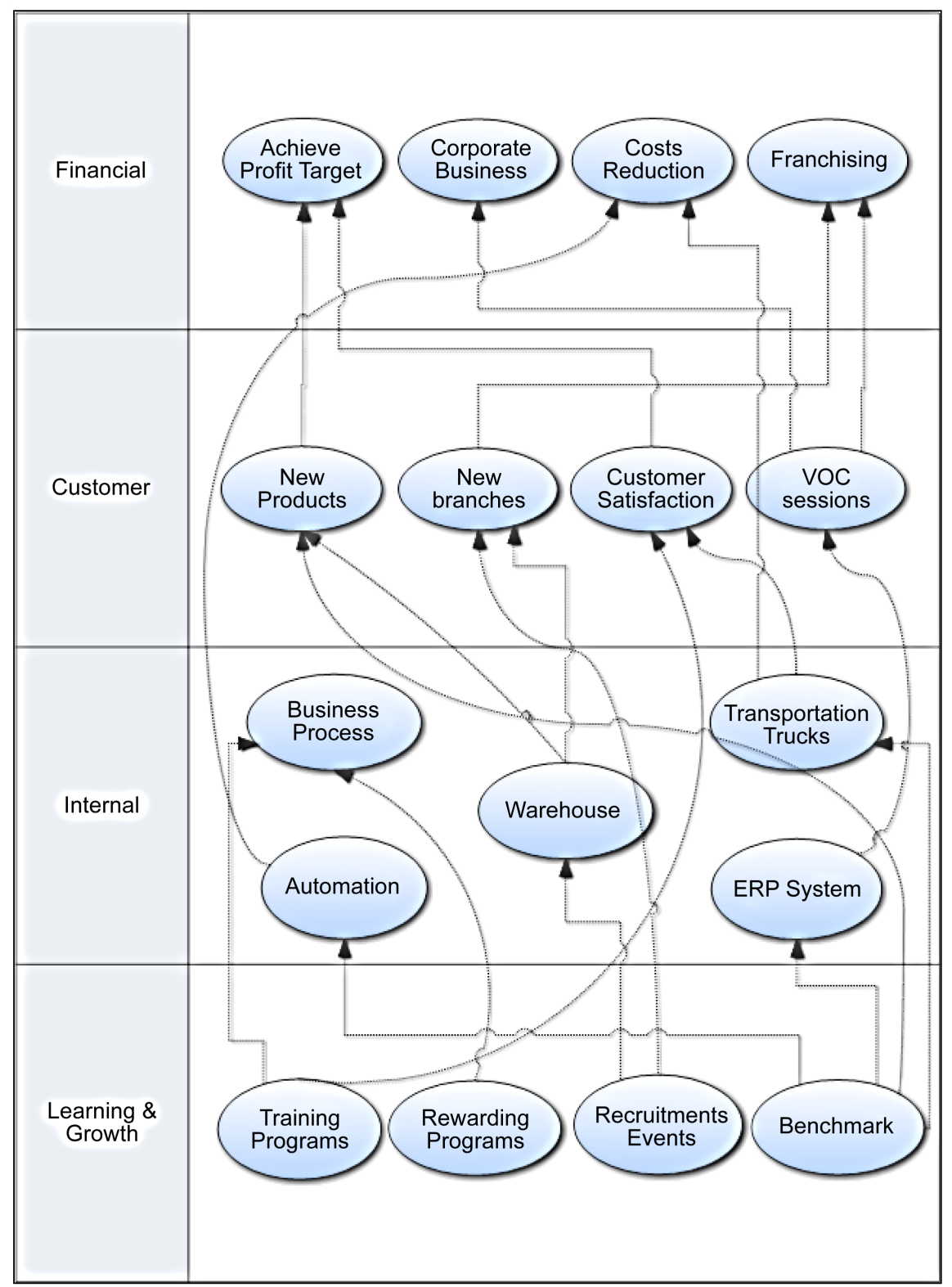

Figure 4. Strategy map.

- KPI: They are the result of one action and directly linked to a strategic objective.

KPIs are set for each operational objective even if there is an intangible objective. The idea is to translate all the objectives into quantifiable measures to diagnose the problem whenever there is a non-desired action occurred. This will help in monitoring the business and in taking corrective initiatives.

The KPIs are set for each operational objective among those four perspectives and are shown in a summarized Table (see Table 5).

\section{6) Evaluation}

Once the KPIs and their targets are set, planner can manipulate with the evaluation period. For example, an exceptive prefers to make a quarterly assessment. Another may prefer to conduct the assessment every six months, etc. 
Table 5. List of all KPIs.

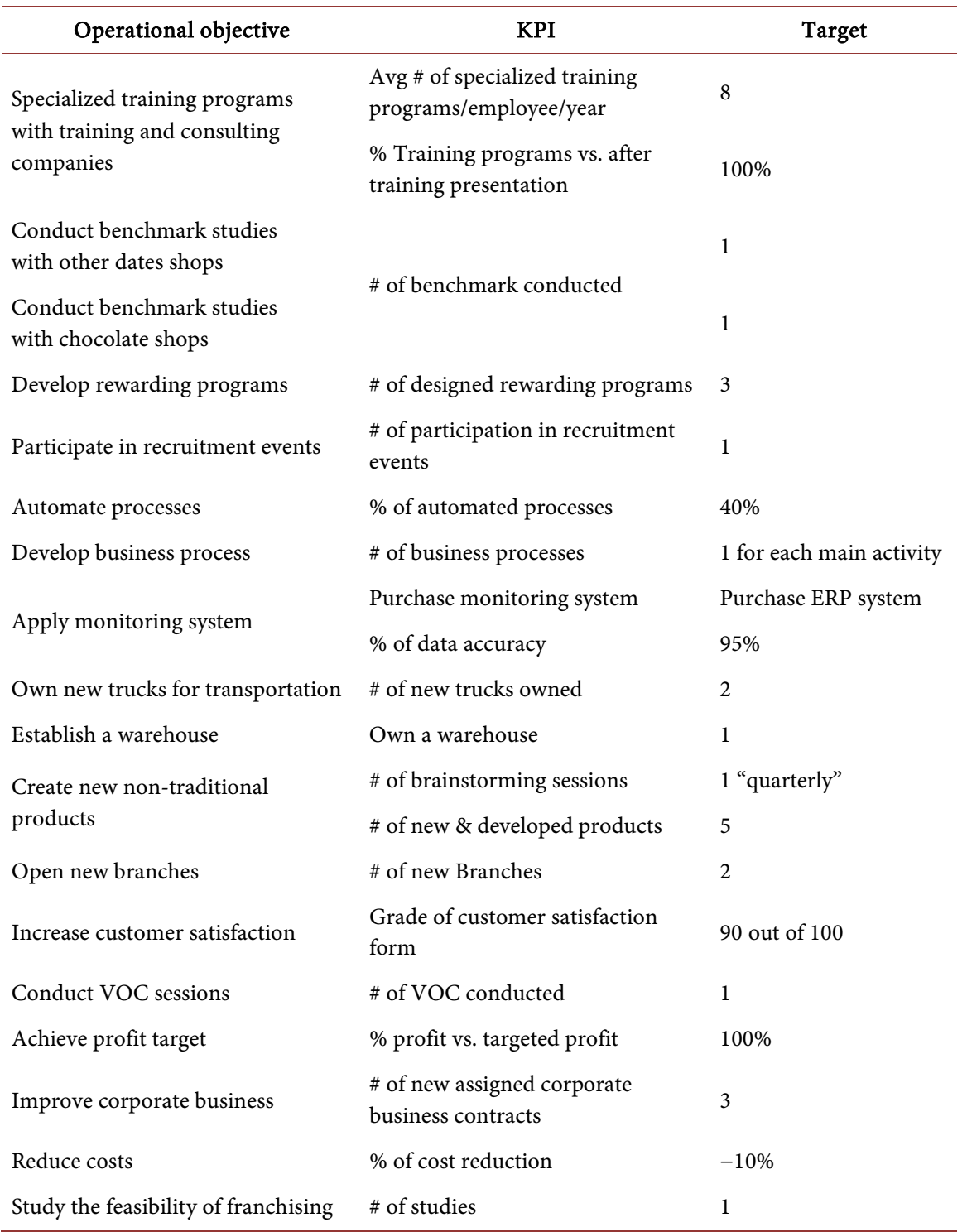

Evaluation is a continuous process. Whenever an executive needs to check the performance progress, the BSC dashboard is his reference. Usually, the KPI dashboard is automated to easily monitor the performance, but unfortunately an automated KPI dashboard is not yet applied in Talah Company.

\subsubsection{Phase III: Continuous Improvement (KAIZEN)}

The last phase of the framework is to build a continuous improvement culture in the company. KAIZEN is the selected technique for making continuous improvements. However, it is important first to build this culture in the company before implementing it. Many organizations fail to do such techniques because their employees do not realize the importance of KAIZEN.

\section{1) KAIZEN Preparation}

Talah Company follows a preparation plan before implementing KAIZEN. See Figure 5. 


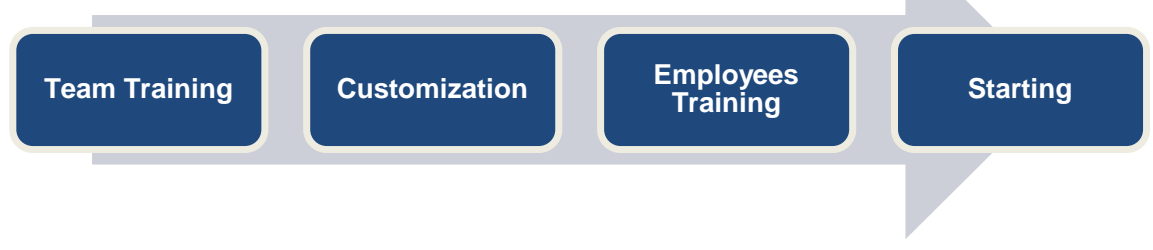

Figure 5. KAIZEN preparation process.

\section{- Team Training}

It is not an easy job to assign a contract with a training and consulting company to train such a large number of employees due to financial issues. Therefore, from the principles of self-development and knowledge sharing it is preferred to choose two qualified persons from each BSC perspectives to be involved in the "training of trainers" program in KAIZEN. These eight persons will be the KAIZEN team in the company.

\section{- Customization}

Scientifically, there are many approaches and forms to implementing KAIZEN. To be more accurate and effective, the KAIZEN team will hold some workshops to customize improvement plans, standard forms and rewarding programs to be more aligned with the company's situation.

\section{- Employees Training}

KAIZEN training workshops contribute to improvement knowledge and the realization of the importance and the implementation methodology.

\section{- Starting}

It is very important to let the employees feel that continuous improvement is one of the company's main values. Some tools such as holding a start-up party for KAIZEN, sending reminders via E-mails, and placing motivation letters on the walls are very helpful in creating such a culture.

\section{2) Two Levels of KAIZEN}

Practically, Talah implements two levels of KAIZEN. One is called "Small KAIZEN", and the other takes a standard "KAIZEN process". "Small KAIZEN" should be the first choice of making things better without any financial input or very little financial input, offering quick improvement. In contrast, the "KAIZEN process" takes time and financial input.

\section{Level (1): Small KAIZEN}

Small KAIZEN concerns very small changes; it focuses on regular daily activities or the work environment. In this kind of continuous improvement, there is no need to obtain approval from higher managements levels. When any employee from any level in the organizations observes that there is a chance to solve a minor problem or to improve on an existing issue, he simply fills a form to show his perception and then obtain the approval immediately from his direct supervisor or manager after a quick review of the situation with the recording of his commission.

The employees can simply record the current situation or problem they are 
facing and add what kind of input and applied solution with a picture or drawing. Finally, the benefits and outputs obtained from the small KAIZEN need to be recorded on the right side of the format with pictorial records (after small KAIZEN). Figure 6 shows one of the examples of using that approach.

\section{Level (2): KAIZEN Process}

The KAIZEN Process is the other process in Talah Company. It differs from the first level because it is not an individual task and usually requires approval form higher management levels.

In the company, this process is conducted every six months and whenever there is an urgent need to make changes. PDCA involves seven main steps as shown in Table 6.

\section{a) Trucks Case}

Here is an example of using KAIZEN Process in Talah Company. The following steps will describe the situation:

- Step (1): Selection of the KAIZEN theme:

Since because it requires a relatively large change as will be shown in the next steps, the level-two "KAIZEN Process" is used for this situation.

- Step (2): Situation analysis:

There are some trucks that transfer between the warehouse and branches. These trucks carry the final products "after being on the dishes and packaged" to the branches. Unfortunately, the product defects during transportation sometimes reach up to $9 \%$. Therefore, the goal is to make some improvements to minimize defection percentage.

\begin{tabular}{|l|l|}
\hline \multicolumn{1}{|c|}{ Department Name: .................. } \\
\hline \multicolumn{1}{|c|}{ Bitle: .................. } & \multicolumn{1}{|c|}{ After Improvement (KAIZEN) Benefits/Outputs } \\
\hline $\begin{array}{l}\text { 1) Problems: } \\
\text { Wasted dates bits during cutting \& filling process }\end{array}$ & New Product \\
2) KAIZEN Points: & \\
Re-use the unutilized dates bits & \\
3) Input: & \\
Milk, Mixer, Flavor \& Dates bits & \\
\hline
\end{tabular}

Figure 6. Talahshake memo. 
- Step (3): Root cause analysis:

The Fishbone Diagram technique is used to identify the root causes for the situation; see Figure 7.

As shown in the figure, there are many possible causes for product defects. Although the focus is narrowed to these causes, the objective is to find the root cause. The KAIZEN team drilled down on each of these causes to investigate the contribution from each cause. The outcome is formulated in a Pareto Diagram, as shown in Figure 8.

Table 6. KAIZEN process.

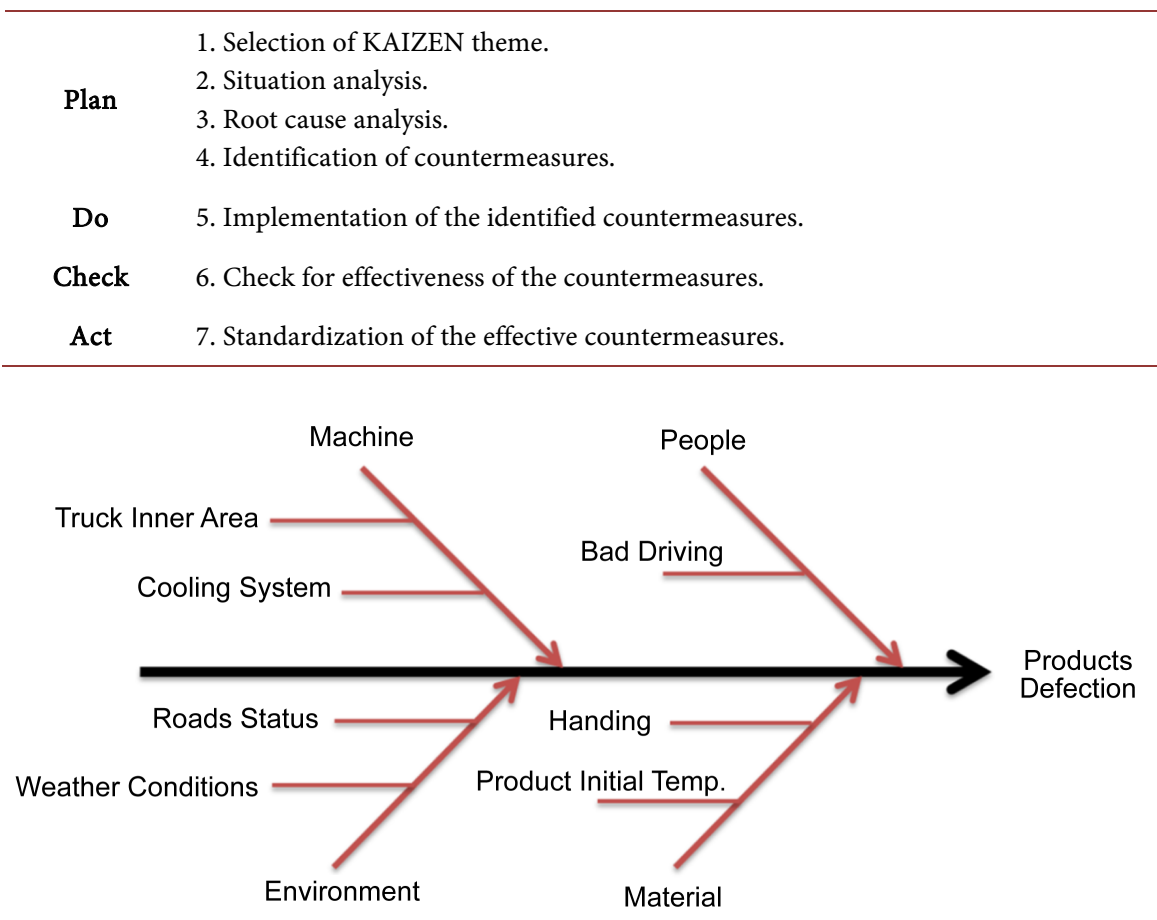

Figure 7. Fishbone diagram for the quality problem in Talah.

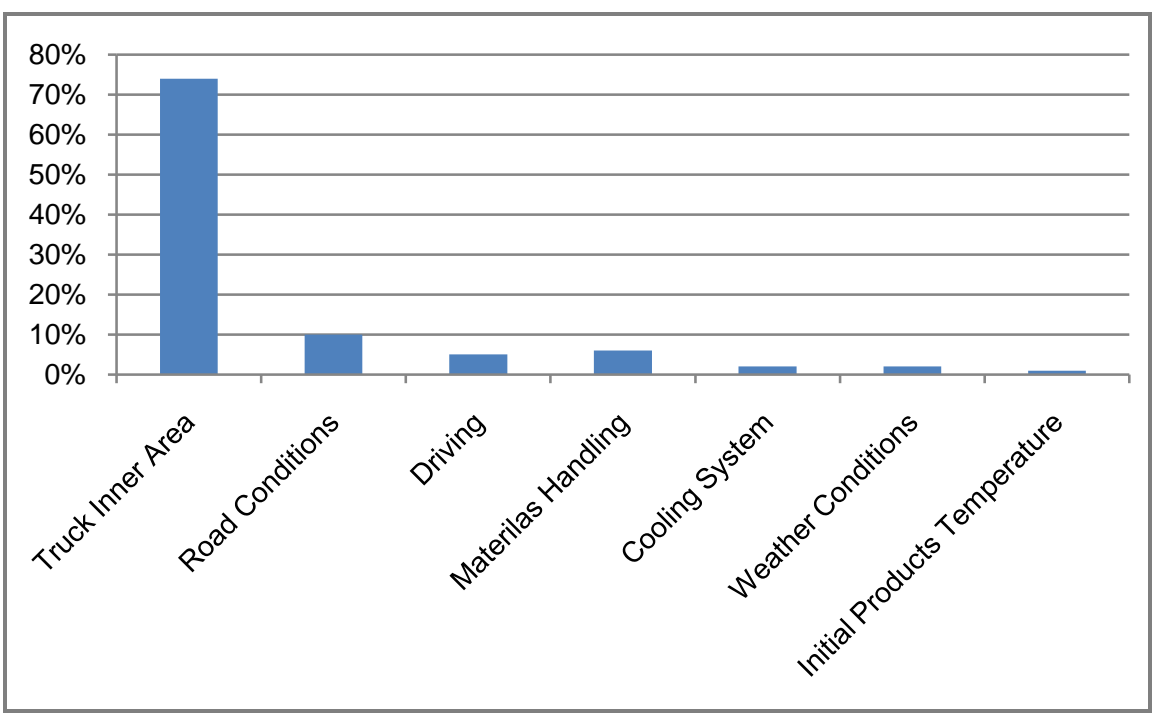

Figure 8. Percentage cont. for various possible causes. 
- Step (4): Identification of countermeasures:

From Figure 8, it is clear that the main cause is related to the truck itself. The question now is "how to enhance the trucks" or in other words "how to expand the area inside the trucks". Some sessions were held to answer this question and find the most effective way to solve the problem.

The final solution was to separate the main products from its complementary stuff, such as dishes and packaging tools. That means two trucks will move to each branch; one provides the products and the other provides complementary materials.

- Step (5): Implementation of the identified countermeasures:

The management made the approval to give all support to apply this new approach during a two-month test period.

- Step (6): Check the effectiveness of the countermeasures:

After the test period, the KAIZEN team checked the performance and concluded the following results:

- The transportation time is reduced by approximately $5 \%$.

- The material handling time is reduced by approximately $10 \%$

- The percentage of defection is minimized to approximately $1 \%-2 \%$.

- Step (7): Standardization of effective countermeasures:

The process of transportation is standardized as follows:

- Two trucks to be moved to each branch, one provides the products "regular truck" and the other "conditioned" provides complementary materials.

- In each branch, a small area operated by two to three workers will be for preparing the products and packaging.

\section{Conclusions}

In the modern world, people can no longer expect large enterprises to guarantee them jobs for life. Individuals are increasingly expected to seek out their own opportunities, actively create value and behave ethically, rather than faithfully follow rules and routines set by others. In particular, today's young people need to learn to be enterprising, both when working for others and when setting up their own businesses. Being enterprising involves taking responsibility for decision making; becoming increasingly self-reliant, pioneering, adventurous, daring, dynamic, progressive, opportunistic and ambitious; and being able to initiate ideas and see them through into action. This study showed a guidance framework for entrepreneurship; it depends on three main pillars, which are the Blue Ocean Strategy (BOS), Balanced Scorecard (BSC) and Continuous Improvement (KAIZEN). The Blue Ocean Strategy guides entrepreneurs to find a new blue ocean away from competition and wars, as is prevalent in business today. It is a way to study the market from competitors' points of view, determine the competing factors, recognize competitors' aspects and then create the differentiation toward a new blue ocean. Moreover, the trade-off between cost and innovation is broken down through the concept of the ERRC grid.

The Balanced Scorecard determines the values, vision, mission, strategic ob- 
jectives and KPIs, which are defined and aligned together. Note that the vision here is affected by the concept of BOS; it will be built in a new blue ocean rather than the vision being built in a red ocean. Furthermore, cascading the strategic objectives into operational objectives and distributing them into four perspectives give a balanced view for a business.

Being stable in the market gives competitors the chance to attack. To be competitive and survivable in today's business, it is crucial to make continuous improvements, as done in this study through the KAIZEN technique. The power of this technique lies in giving all the employees "regardless of their grades or levels in the organization" the motivation and chance to contribute in the continuous improvement process. People who perform a certain task will be the most knowledgeable about that task, so by involving them and showing confidence in their capabilities, ownership of the process is raised to its highest level.

Finally, the output of this study is a designed framework that integrates the three main techniques. To cover the gist of many successive businesses today, which is idea innovation, business strategy, strategy measurements and improvement. The framework is implemented in Talah Aljood Company as a case study to give a clear perception about the implementation of the practical methodology.

\section{References}

[1] World Bank (2014) Doing Business 2014. World Bank Group, Washington DC.

[2] Schwab, K. and Sala-i-Martín, X. (2014) The Global Competitiveness Report 20132014. World Economic Forum, Geneva, Switzerland.

[3] Drucker, P.F. (1985) Innovation and Entrepreneurship. Harper Collins, New York.

[4] Bygrave, W. and Zacharakis, A. (2011) Entrepreneurship. John Willy \& Sons, Inc., Babson Park.

[5] Karlsson, C., Friis, C. and Paulsson, T. (2004) Relating Entrepreneurship to Economic Growth. CESIS Electronic Working Paper Series, 13 September.

[6] Parker, S.C. (2004) The Economics of Self-Employment and Entrepreneurship. Cambridge University Press, Cambridge. https://doi.org/10.1017/CBO9780511493430

[7] Clare, L., Pottie, G. and Agre, J. (1999) Self-Organizing Distributed Sensor Networks. Proceedings of SPIE, 3713, 229-237. https://doi.org/10.1117/12.357138

[8] Ács, Z.J. and Audretsch, D.B. (2005) Introduction to the Handbook of Entrepreneurship Research. In: Ács Z.J. and Audretsch D.B., Eds., Handbook of Entrepreneurship Research, Springer, US, 11-19. https://doi.org/10.1007/0-387-24519-7_1

[9] Kim, W.C. and Mauborgne, R. (2005) Blue Ocean Strategy: How to Create Uncontested Market Space and Make Competition Irrelevant. Harvard Business School Press, Boston.

[10] Kaplan, R.S. and Norton, D.P. (1996) Using the Balanced Scorecard as a Strategic Management System. Harvard Business Review, 74, 75-85.

[11] Imai, M. (1986) Kaizen: The Key to Japan's Competitive Success. McGraw-Hill Education, New York.

[12] Soliman, A.A. and Al-Saleh, F.A. (2001) Date Consumption Behaviour among the Saudis. Kingom of Saud University, Saudi Arabia. 
Submit or recommend next manuscript to SCIRP and we will provide best service for you:

Accepting pre-submission inquiries through Email, Facebook, LinkedIn, Twitter, etc. A wide selection of journals (inclusive of 9 subjects, more than 200 journals)

Providing 24-hour high-quality service

User-friendly online submission system

Fair and swift peer-review system

Efficient typesetting and proofreading procedure

Display of the result of downloads and visits, as well as the number of cited articles Maximum dissemination of your research work

Submit your manuscript at: http://papersubmission.scirp.org/

Or contact ajibm@scirp.org 